\title{
Surgical approach of orbital subperiosteal abscess associated with the orbital fracture
}

\author{
Abordagem cirúrgica a abscesso orbitário \\ subperiosteal associado à fratura de órbita
}

Antonio Dionízio de Albuquerque Neto', Thaisa Reis de Carvalho Sampaio ${ }^{1}$, Darlan Kelton Ferreira Cavalcante', Luciano Leocádio Teixeira Nogueira Filho², Pedro Thalles Bernardo de Carvalho Nogueira ${ }^{3}$, José Rodrigues Laureano Filho $^{4}$

\begin{abstract}
The proximity of the orbital cavities to the air spaces of the face results in the occurrence of orbital infections resulting from sinusitis. Children with debilitated nutritional status are especially vulnerable. Clinically presents the inflammatory signs, and visual acuity deficit, diplopia, ophthalmoplegia and proptosis. Might also lead to severe complications such as cavernous sinus thrombosis and intracranial abscess. These infections can be classified according to their severity. Imaging tests of choice for the diagnosis and planning of cases include axial and coronal cuts of computed tomography. Treatment should be compatible with the severity of the case, taking into account the side effects of the antibiotics used. The objective of this paper is to report a case of a pediatric patient who sustained facial trauma resulting in fracture of the upper orbital rim and subsequently developed orbital subperiosteal abscess. We discuss the clinical and imaging criteria for successful diagnosis and treatment.
\end{abstract}

Keywords: Orbit/injuries; Abscess/etiology; Ophthalmoplegia; Sinusits/complications; Infection; Case reports

\section{RESUMO}

Devido à proximidade das cavidades orbitárias com os espaços aéreos da face, a ocorrência de infecções advindas de sinusites para a órbita são frequentes. Acometem mais comumente crianças com estado nutricional debilitado. Clinicamente apresentam os sinais flogísticos, além de déficit visual, diplopia, oftalmoplegia e proptose. Podem evoluir com complicações graves, como trombose do seio cavernoso e abscesso intracraniano. Estas infecções podem ser classificadas de acordo com sua gravidade. Os exames de imagem de escolha para o diagnóstico e planejamento dos casos são cortes axiais e coronais de tomografia computadorizada. O tratamento deve ser compatível com a gravidade do caso e reação do organismo à antibioticoterapia. O objetivo deste artigo é relatar um caso clínico de paciente pediátrico que após trauma em face foi acometido por fratura em rebordo orbitário superior e desenvolveu posteriormente abscesso orbitário subperiosteal, discutindo os critérios clínicos e imaginológicos para o diagnóstico e a devida condução do caso.

Descritores: Órbita/lesões; Abscesso/etiologia; Oftalmoplegia; Sinusite/complicações; Infecção; Relatos de casos

${ }^{1}$ Course of Study of Odontology, Universidade Federal de Alagoas, Maceió, AL, Brazil.

${ }^{2}$ Multidisciplinary Residency in Surgery and Oral and Maxillofacial Traumatology, Hospital Universitário Oswaldo Cruz, Universidade de Pernambuco, Camaragibe, PE, Brazil.

${ }^{3}$ Masters Program, Faculdade de Odontologia de Pernambuco, Camaragibe, PE, Brazil.

${ }^{4}$ Faculdade de Odontologia de Pernambuco, Camaragibe, PE, Brazil.

The authors declare no conflicts of interest

Received for publication 12/04/2015 - Accepted for publication 29/04/2015 


\section{INTRODUCTION}

$\mathbf{T}$ The orbital content is closely related to the paranasal sinuses. Because of this anatomical relationship, the most common etiological factor for orbital infections is sinusitis, particularly ethmoid sinusitis. They may also result from the extension of periorbital infection and direct inoculation by trauma or anachoresis. The patients who most commonly suffer from this disease are children, especially in a poor nutritional condition..$^{1-3}$

The orbital abscess is clinically presented in most cases with local pain, edema, lid erythema and fever. The main findings are visual changes such as diplopia, ophthalmoplegia, central retinal artery occlusion, increased intraorbital pressure, proptosis, optic nerve neuropathy, ocular dystopia and vision loss (blindness). If not promptly diagnosed and treated they can develop to severe complications such as bone involvement, cavernous sinus thrombosis, brain abscess, meningitis, septic embolism, neurological sequelae and death. ${ }^{4}$

Treatment usually requires hospitalization, multidisciplinary assessment and broad-spectrum intravenous antibiotic therapy. The surgical indication is essential in cases of abscess in patients with visual impairment and who do not respond to the initial medical treatment. ${ }^{5}$

\section{Objective}

Report a case of orbital infection in a pediatric patient treated at the General Hospital of the State of Alagoas.

\section{Case Report}

Male patient, 11 years old, victim of sports accident presenting trauma in the face resulting in linear fracture of the upper orbital rim. Upon hospital admission 4 days after the trauma, he was in fever, pain complaints in the left orbital region, strong eye proptosis, eyelid ptosis, ophthalmoplegia, chemosis and decreased visual acuity. (Figures 1-A e 1-B). He reported previous history of chronic sinusitis.

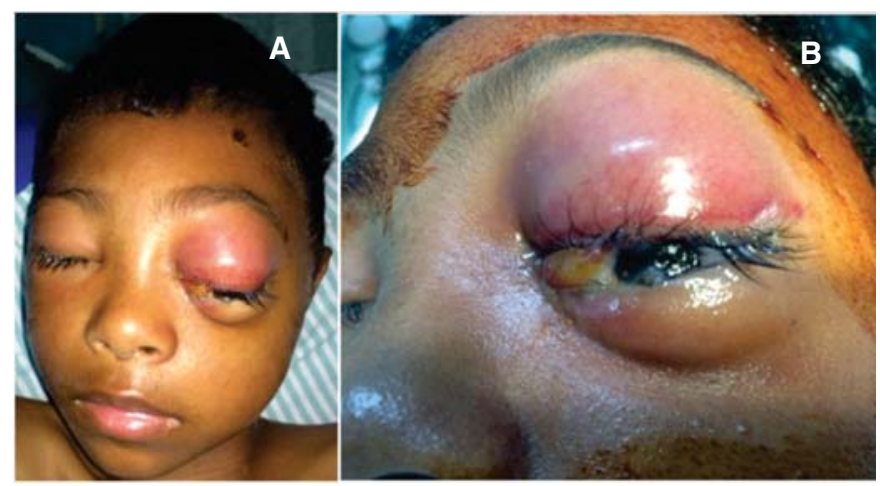

Figures 1-A e 1-B: He reported previous history of chronic sinusitis.

A CT scan (Figure $2 \mathrm{AD}$ ) was requested, where there were hyperdense images in the left sinus spaces suggesting thereby that the infection affected the paranasal sinuses (ethmoid and maxillary), which was consistent with the patient's history of chronic sinusitis. The location of the orbital abscess was observed, with anterior-inferior displacement of the left eyeball due to increased internal pressure caused by infection located at the upper part of the orbit and muscle thickening due to edema.
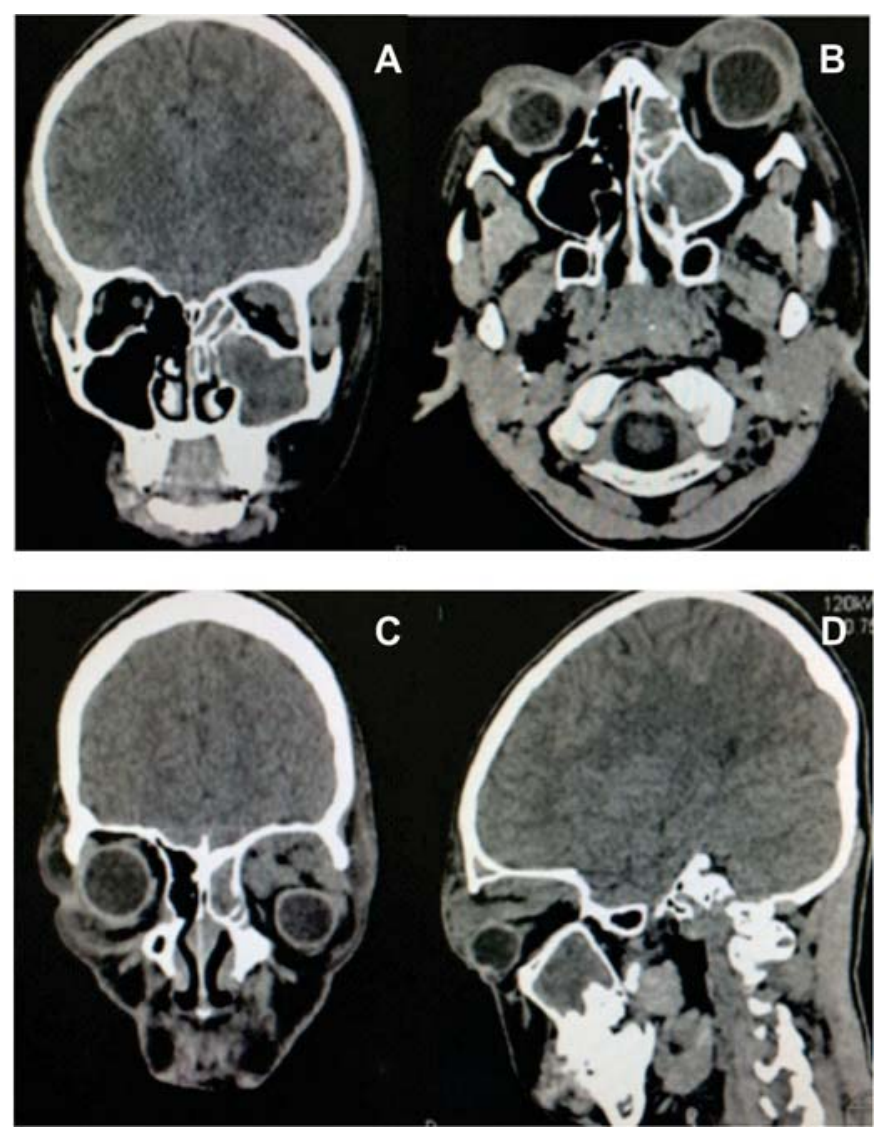

Figure 2. A-D: Face CT in the axial, coronal and sagittal cuts, where there is exophthalmos of the left eyeball, opacification of paranasal sinuses and hyperdense image in the upper left part of the orbit suggestive of content arising from infection and thickening of the muscles of the ocular motility.

Based on clinical, laboratory and CT findings, the subperiosteal orbital abscess was diagnosed. The initial antibiotic therapy started empirically with Ampicillin associated to Sulbactan and Clindamycin. The laboratory tests showed leukocytosis with left deviation and substantial increase in the number of neutrophils and lymphocytes. Although the culture was held through conjunctival smears, it would not be feasible to wait for the results to decide upon the surgery due to the imminent risk of severe complications and development of the disease. After three days of drug treatment and without involution of the condition, the patient underwent a surgical procedure to treat the infection. After five days, the culture of conjunctival smears showed high colonization of Streptococcus sp and Staphylococcus sp.

Under general anesthesia, drainage and orbital decompression were made via superciliary incision and divulsion blunt of the tissues to gain access to the subperiosteal region of the orbital roof with abundant drainage of the purulent exudate (Figure 3A).

The fracture line in this rim line was evident during surgery (Figure 3B), without the need for treatment due to be properly 
aligned and without mobility. The drainage of the maxillary sinus was performed with a Cadwell Luc access, and abundant irrigation with saline solution (Figure 3D). Postoperatively, broad-spectrum antibiotics were given: ampicillin associated to Sulbactan, clindamycin and oxacillin.

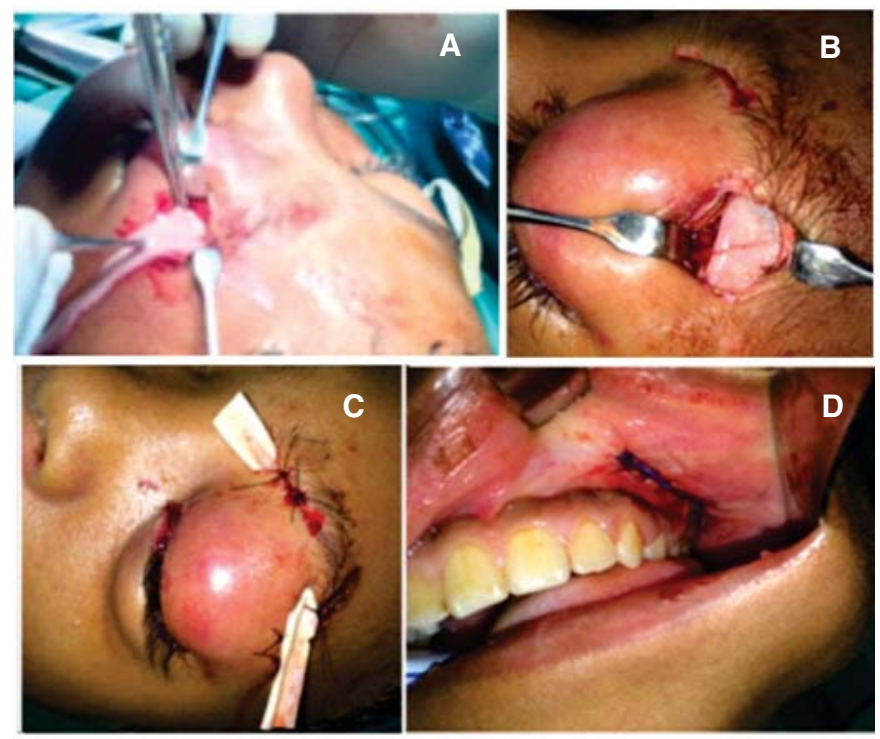

Figure $3 \mathbf{A}$ - Soon after obtaining access to the subperiosteal region of the upper wall of the orbit was the drainage onset of abundant purulent exudate. Figure 3 B - Linear fracture in the upper orbital rim. Figure $3 \mathbf{C}$ - Immediate post-surgical with drain installed for drainage of remnants and disorganization of the infectious content. Figure 3 D - Suture held after draining through Cadwell Luc access of the left maxillary sinus.

The patient recovered well after the drainage and orbit decompression, with almost complete remission of the clinical profile within a period of 10 days. Clinical exams showed that the patient presented transient reversal of amaurosis. Preoperatively, he did not respond to the test of counting fingers, and only showed light perception. A thorough assessment of visual acuity was impaired due to the edema. Ten days after surgery the patient already showed normal visual acuity (20/20). Referring to the ocular motility tests performed, a regression of motor function of the affected eyeball was found, without diplopia or visual sequelae. In 90-day follow-up the patient showed no visual and oculomotor deficits. No sequelae were observed, except a slight scar on the upper eyelid region. (Figures 4A-D)

\section{Discussion}

Nasosinusal infections are highly prevalent clinical entities, and may develop with potentially severe complications. Acute complications have higher incidence in children due to common anatomical factors and frequent infections of the upper respiratory tract. The orbital impairment secondary to rhinosinusitis is due to the direct extension of the infection by ophthalmic vein thrombophlebitis, facilitated by the absence of valves in this venous system, the weakness of separation between the orbital contents and the ethmoidal labyrinth, the presence of
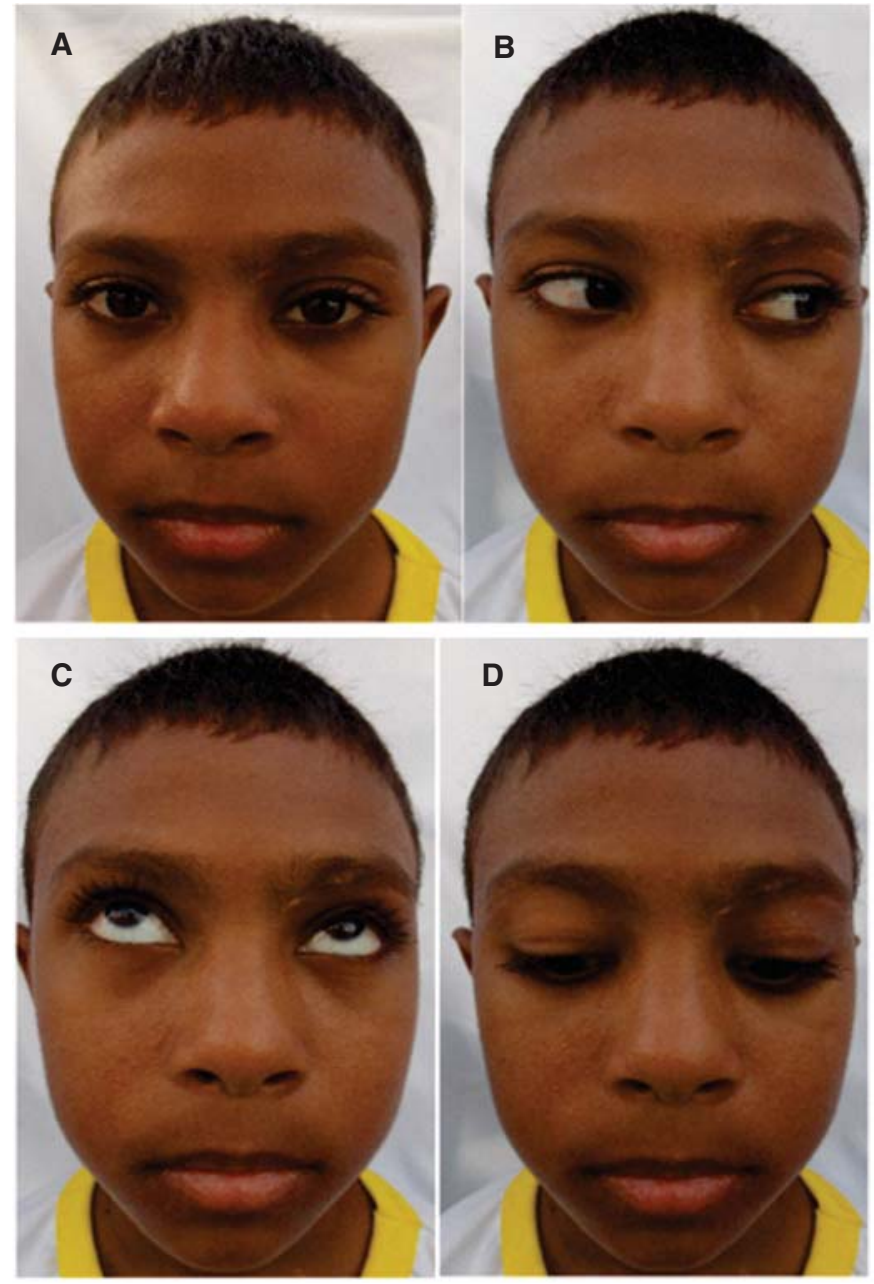

Figure 4A: Front aspect, 90 days after surgery, with a slight scar on left eyebrow region. Figure 4 B, C and D: Movements of the eyeball showing remission of ophthalmoplegia and preservation of eye motilidadde with visual acuity preserved without motor and visual deficits.

large number of sutures (open in the children), the bone dehiscence of the papyraceous blade, wider neurovascular foramen on the medial wall of the orbit and more porous bones, thus facilitating the spread of the desease..$^{2,5-7}$ In the present case the patient was affected by a trauma resulting in orbital fracture with subsequent hematoma formation in the region, and due to anatomical peculiarities of the patient it was colonized by microorganisms of the previously infected sinuses.

A literature search showed the Haemophilus influenza type $\mathrm{B}$ as the microorganism most commonly found in blood culture. Staphylococcus $s p$ was the pathogen most commonly found in the maxillary sinus aspirated secretion. The microorganisms most commonly found in orbital infections are species of Streptococcus and Staphylococcus, all susceptible to clindamycin or vancomycin. However, due to the indiscriminate use of antibiotics, the development of resistance, and the constant changes in the profile of these micro-organisms, there is a growing need for studies on the microbiological changes present in these infections. In this case the culture results were consistent with the literature, and treatment followed preconized protocols. ${ }^{8}$

Computed tomography has 78 to $92 \%$ of detection sensitivity, with absolute request indication when in suspicion of 
more serious complications. The images obtained are of the structures composing the orbit, neuro-vascular and muscles. An MRI may be requested as a complement when necessary.,7,9

Chandler et.al., described the extent of the orbital infection in five levels, being it widespread by professionals. I - periorbital cellulitis, II - orbital cellulitis, III - subperiosteal abscess, IV orbital abscess, $\mathrm{V}$ - cavernous sinus thrombophlebitis. In our case, the patient had a subperiosteal abscess, whose main symptoms are reduced visual acuity, decreased movement of the extraocular muscles that occurs secondary to edema or spasm of the muscles, and proptosis and deviation of the lateral-inferior eyeball. It is important to emphasize the importance of the periosteum as a barrier against the progression of the infection to the orbital space (extraconal and intraconal) and later intracranial complications. ${ }^{4,10}$

The decompression and drainage surgery should be used to evidence the abscess on CT - Chandler III, decreased visual acuity, signs of infection progression with clinical treatment, recurrence and involvement of the contralateral eye. As disadvantages related to the conventional drainage technique we can mention unfriendly aesthetics, risk of damage to noble anatomical structures, and higher morbidity in the postoperative period, when compared to the drainage via endoscope. Normally, the visual acuity is recovered a few days after drainage; however, ocular motility and complete recovery of the condition can take up to 3 months due to residual edema in the muscle fibers. In our case we performed a double incision in the eyebrow region, divulsion blunt of the tissue and approach of the subperiosteal region of the orbit to allow drainage of purulent content and orbital decompression. There was a complete remission of signs and symptoms in about 20 days. ${ }^{10-12}$

\section{Final Considerations}

The authors conclude that an early diagnosis by means of clinical and imaging findings along with an opportune and appropriate surgical approach are essential to the success and cure of this particular type of infection. The way this case was dealt followed these principles, and so we could see the success of the short and long term treatment. The patient remains in regular follow-up.

\section{Corresponding author:}

University of Pernambuco - Odontology College of Pernambuco Av. Gal. Newton Cavalcanti,1.650. Tabatinga, Camaragibe Pernambuco - Brazil - ZIP Code 54753-220

E-mail: dr.pedrobmf@gmail.com

\section{Errata}

In the scientific article "Surgical approach of orbital subperiosteal abscess associated with the orbital fracture" the authors: Antonio Dionízio Albuquerque Neto, Thaisa Reis de Carvalho Sampaio, Darlan Kelton Ferreira Cavalcante, Luciano Leocádio Teixeira Nogueira Filho, Pedro Thalles Bernardo de Carvalho Nogueira, José Laureano Rodrigues Filho, published in the Journal of Ophthalmology in the edition of September-October 2015 (Rev Bras Oftalmol. 2015; 74 (5): $315-8$ ) in its digital version in English, 315 pages ( English title ) and 317 ( header) , which reads : orbitalsubperiosteal, read: orbital subperiosteal. 